\title{
De accountant en toekomstverwachtingen
}

De accountant spreekt de waarheid, maar hij is geen waarzegger.

De redactie heeft in het raam van dit nummer van het MAB over 'Planning en Forecasting' de vraag opgeworpen: welke voorspellende inhoud heeft de accountantsverklaring?

Bij de bespreking van deze vraag stel ik mij voor in het bijzonder aandacht te besteden aan:

$a$. de accountantsverklaring omtrent de jaarrekening van een onderneming betreffende een verstreken boekjaar;

b. de accountantsverklaring resp. mededeling met betrekking tot toekomstverwachtingen uitgesproken door de bestuurders van een onderneming.

Voorts beperk ik mij tot verklaringen en mededelingen van de openbare accountant.

Verklaringen van interne accountants hebben in het besloten verkeer hun eigen merites. Ik acht mij echter niet competent om daarover uitspraken te doen.

\section{De accountantsverklaring omtrent de jaarrekening van een onderneming}

1. De accountantsverklaring heeft op het eerste gezicht betrekking op een samenstel van bescheiden, waarin niet anders dan historische feiten zijn vastgelegd. De jaarrekening betreft immers een verstreken boekjaar met de daarin behaalde resultaten en een vermogen per een datum, die eveneens gepasseerd is. De accountantsverklaring kan derhalve geen voorspellende inhoud hebben, zo is men geneigd op voorhand te concluderen.

Deze conclusie zou echter te snel getrokken zijn. Bij het samenstellen van een jaarrekening kan namelijk de toekomst niet buiten beschouwing worden gelaten.

Een jaarrekening kan niet zonder meer middels een rekenkundige bewerking uit de boekhouding worden afgeleid. Eerst komt de waardering van de activa en passiva aan de orde. De toekomstverwachtingen van de ondernemingsleiding zijn daarbij van groot belang. Dit geldt voor tal van balansposten.

De waarde van duurzame produktiemiddelen is onder meer afhankelijk van de geschatte levensduur en van de verwachtingen ten aanzien van de mogelijkheden van een productieve aanwending. 
Het activeren van, m.a.w. het toekennen van een waarde aan, gemaakte researchkosten is slechts reëel indien er kansen zijn dat van het resultaat van researcharbeid een nuttig gebruik zal kunnen worden gemaakt.

De waarde van onderhanden werk hangt af van het resultaat dat na gereedkomen van het werk wordt behaald. Wordt een verlies ingeschat dan is daarmede als regel op de balansdatum reeds rekening te houden. Voorraden kunnen overeenkomstig het bij de onderneming gebruikelijke waarderingssysteem worden gewaardeerd mits vastgesteld is dat voldoende rekening is gehouden met incourantheid, hetgeen inhoudt dat wordt begroot op welke termijn de voorraad op normale wijze is af te wikkelen. De volwaardigheid van vorderingen blijkt pas definitief na betaling. Bij de jaarafsluiting dient het risico van oninbaarheid te worden getaxeerd.

De grootte van voorzieningen voor specifieke risico's kan veelal slechts worden bepaald indien de mate van risico in de toekomst zo goed mogelijk is geëvalueerd.

Uit deze opsomming blijkt duidelijk dat bij de waardebepaling van vele balansposten verwachtingen, schattingen en taxaties van het toekomstig verloop van elk dezer posten van beslissende betekenis zijn. En daarmede bepaalt het inzicht in de toekomst tevens mede het beeld dat de gehele jaarrekening geeft.

Dit inzicht dient niet alleen bij de ondernemingsleiding te bestaan. Ook de accountant behoort zich met toekomstverwachtingen bezig te houden en hij zal in grote lijnen het inzicht van de leiding moeten delen; anders kan hij niet tot een goedkeurende verklaring komen.

Meestal is de accountant in staat op basis van te verrichten onderzoek het benodigde inzicht te verkrijgen. Hij kan kennis nemen van de gang van zaken ná balansdatum, begrotingen bestuderen, de ontwikkelingen in de economie van het land en de van belang zijnde bedrijfstakken volgen, correspondentie over omstreden posten nagaan en wat dies meer zij. Indien dit onderzoek bevredigend verloopt, anders gezegd indien de accountant met de toegepaste waarderingen voorzover bepaald door toekomstschattingen instemt - en ook overigens zijn onderzoek voldoende zekerheid verschaft - kan hij een goedkeurende verklaring geven.

De vraag is nu: betekent deze verklaring waarin toekomstverwachtingen zijn verdisconteerd een voorspelling van de accountant dat alle opgevoerde debiteuren zullen betalen, dat er voldoende bezetting van het productieapparaat zal zijn om economisch te kunnen draaien, dat de gevormde voorzieningen toereikend zullen zijn om alle risico's te dekken enz. enz.?

De vraag zo stellen is tevens haar beantwoorden. Natuurlijk voorspelt de accountant al deze ontwikkelingen niet. $\mathrm{Hij}$ is geen profeet of waarzegger, die met stelligheid kan beweren dat bepaalde feiten zich zullen voordoen. In deze zin heeft de accountantsverklaring derhalve geen voorspellende inhoud.

De verklaring houdt echter wel (onder meer) het oordeel van de accountant in, dat voorzover toekomstverwachtingen van invloed zijn op het beeld dat de jaarrekening geeft deze op verantwoorde wijze in de waardering van de afzonderlijke posten van de jaarrekening tot uitdrukking zijn gebracht. 
2. In het vorige punt is aangenomen dat het accountantsonderzoek met betrekking tot de invloed van toekomstschattingen op waarderingen bevredigend is verlopen.

Dit behoeft echter niet steeds het geval te zijn. Uit onvoldoende zicht op de toekomst kunnen er onzekerheden voor de accountant blijven bestaan. En als het dan gaat om één of meer posten die op het beeld dat de jaarrekening oproept van invloed zijn, dient de accountant hiervan blijk te geven in zijn verklaring, ook in het geval dat de onzekerheden in de jaarrekening zelve goed zijn verwoord.

Daartoe staan hem ten dienste de goedkeurende verklaring onder voorbehoud en de verklaring van oordeelonthouding.

Bij de verklaring onder voorbehoud gaat het blijkens artikel 13, lid 2 GBR 'om bedenkingen of onzekerheden ter zake van de verantwoording die aan de goedkeurende strekking van de verklaring niet wezenlijk afbreuk doen, doch die van zodanig gewicht zijn dat zij in de verklaring tot uitdrukking dienen te worden gebracht'.

Bij de oordeelonthouding zijn er zoveel onzekerheden dat de accountant noch een goedkeurend noch een afkeurend oordeel kan uitspreken over de gehele verantwoording. Hij onthoudt zich van een oordeel.

De bedoeling is duidelijk; indien een enkele niet onbelangrijke post door de accountant niet te beoordelen is kan hij de verklaring met voorbehoud geven.

Zijn er echter te veel onzekerheden dan bedient hij zich van de verklaring van oordeelonthouding, waarin de onzekerheden worden uitgelegd, veelal onder verwijzing naar de inhoud van de jaarrekening.

Is in deze verklaringen een voorspellende inhoud te vinden? Naar mijn oordeel niet. De zaken waaromtrent de accountant uit hoofde van een te vage toekomst onzeker is worden vermeld. Dit wil echter niet a contrario zeggen dat de accountant omtrent de posten waarvan hij niets zegt voorspellingen doet. Daarvoor geldt ook hetgeen in het vorige punt is opgemerkt, niet minder maar ook niet meer, nl. dat de accountant van oordeel is dat voorzover toekomstverwachtingen van invloed zijn op het beeld dat de jaarrekening geeft deze op verantwoorde wijze zijn verwerkt of vermeld.

In het kader van de beschouwingen in dit artikel meen ik met het vorenstaande over de verklaring met voorbehoud en de verklaring van oordeelonthouding te kunnen volstaan. Daarmee wil ik echter geenszins beweren dat de toepassing van deze verklaringen in de praktijk zonder problemen is.

Recente NIvRA-publicaties ${ }^{12}$ waarover het laatste woord nog niet is gezegd wijzen op het tegendeel.

Aan de afkeurende accountantsverklaring die in de theorie en de GBR wordt genoemd als mogelijke accountantsverklaring wil ik geen woorden wijden. In de praktijk komt deze verklaring - althans volgens mijn, uiteraard beperkte, waarneming - niet voor. 
3. Ten slotte is het nodig aandacht te geven aan de zgn. voorwaardelijk goedkeurende verklaring bij de jaarrekening van ondernemingen met continuiteitsproblemen ${ }^{3}$.

Ik heb deze verklaring in dit deel van mijn betoog voor het laatst bewaard omdat daarbij de toekomstverwachtingen in optima forma aan de orde komen. In het voorgaande ging het steeds om toekomstige ontwikkelingen, die van zeer verscheiden aard kunnen zijn, voorzover van belang voor de waardering van afzonderlijke posten in de jaarrekening. Bij ondernemingen die in ernstige onzekerheid verkeren omtrent hun voortbestaan gaat het om de waarderingen van vele posten in de jaarrekening die afhankelijk zijn van één overheersende toekomstvisie, $\mathrm{nl}$. de verwachting omtrent de continuilteit van de onderneming. De waarderingsgrondslagen zijn gebaseerd op de veronderstelling van continuïteit. Indien deze veronderstelling niet meer opgaat zijn nagenoeg alle waarderingsgrondslagen discutabel. Hoe de accountant zijn weg in verschillende te onderscheiden situaties zou behoren te vinden is in de Meningsuiting $\mathrm{nr}$. 1 van het College voor Beroepsvraagstukken van het NIvRA uiteengezet. Ik meen een resumé van deze uiteenzetting thans achterwege te kunnen laten. Recent is hieraan naar mijn mening nog voldoende nadere aandacht gegeven ${ }^{4}$.

Zeer belangwekkend voor het onderwerp van deze beschouwing is het artikel van Van Frederikslust en Van Hoepen in het MAB 1981 blz. 561, eveneens opgenomen in dit bijzondere nummer.

$\mathrm{Om}$ te bepalen in welke situatie van onzekerheid zich de onderneming bevindt dient de accountant volgens de Meningsuiting een korte termijn liquiditeitsprognose op te stellen. De continuïteit wordt nl. uiteindelijk bepaald door de liquiditeit. 'Het is het gebrek aan liquiditeit dat tot liquidatie dwingt'.

De Meningsuiting geeft niet aan op welke wijze de liquiditeit te prognotiseren is, hetgeen er naar het oordeel van de genoemde schrijvers toe leidt dat de ' + ' en 'o' situaties niet scherp genoeg worden onderscheiden'.

$\mathrm{Zij}$ geven in het vervolg van hun artikel twee benaderingen aan, die tot scherpere onderscheidingen kunnen leiden.

Beide benaderingen trachten een voorspelling te geven van het kassaldo aan het einde van een periode van stel 3 tot 6 maanden. De uitkomst van deze voorspelling is mede bepalend voor de situatie waarin de onderneming zich bevindt.

De continuïteit wordt bedreigd wanneer het kassaldo negatief wordt. De eerste benadering van het kassaldo (y) na verloop van een zekere periode (t) geschiedt door aan het huidige kassaldo toe te voegen het verschil tussen ontvangsten en uitgaven in periode $t$. Een voorspelling van $y_{t}$ kan dan plaatsvinden door middel van een voorspelling van de verschillende onderdelen (variabelen) van de ontvangsten en uitgaven. De accountant kan trachten het waardebereik van de individuele variabelen en hun kansverdeling te schatten.

Deze benadering lijkt veel op de liquiditeitsbegrotingen, die men in de praktijk wel aantreft - dan echter zonder veel aandacht voor het waardebereik der variabelen en hun kansverdeling.

De tweede benadering wordt aangeduid als 'discriminantanalyse'. Het kas- 
saldo $y_{t}$ wordt voorspeld op basis van waarnemingen betreffende een willekeurige steekproef van ondernemingen, die representatief geacht kan worden voor de te beschouwen groep van ondernemingen. Deze benadering is uitvoerbaar als het verband tussen $\mathrm{y}$ en de variabelen stabiel is in de $t i j d^{6}$.

De beschrijving van beide benaderingen, toegelicht met een aantal algebraïsche formules en diagrammen, vestigt in eerste aanleg - althans bij mij - de indruk van een grote exactheid bij het voorspellen. De stellige formulering van de conclusies in punt 8 werkt deze indruk in de hand: 'op betrekkelijk eenvoudige wijze kan worden vastgesteld' en 'kan worden bepaald hoe sterk de bedreiging van de continuïteit is' en 'in het bijzonder wordt de volgens de Raad van Beroep noodzakelijke objectieve beoordeling van de voorwaarde voor afgifte van de voorwaardelijk goedkeurende verklaring mogelijk gemaakt'.

Nadere beschouwing doet echter de aanvankelijke gedachte van exacte voorspellingsmogelijkheden verdwijnen.

Over de eerste benadering zeggen de schrijvers zelf: de voorspelling van de waarden van de variabelen "kan worden gebaseerd op ervaringen van de accountant en/of op subjectieve verwachtingen, die geëxtrapoleerd worden naar de toekomst'.

En de tweede benaderingswijze is gebaseerd op enkele veronderstellingen die onjuist kunnen zijn: een representatief geachte steekproef; een stabiel verband in de tijd tussen y en de variabelen. Hieruit blijkt wel dat de schrijvers niet pretenderen methoden aan te geven, die toekomstige liquiditeit met zekerheid kunnen doen voorspellen. In dit licht bezien komen de krachtige bewoordingen van de geciteerde conclusies mij wel iets te stellig voor.

Overigens apprecieer ik de handreikingen die zijn gegeven in de beschreven benaderingen ter beantwoording van de liquiditeitsvraag. Voor degenen die in staat en bereid zijn zich de nodige wiskundige technieken eigen te maken kunnen het in voorkomende gevallen praktische hulpmiddelen zijn. Een precieze voorspelling van een toekomstige kaspositie wordt er niet door mogelijk gemaakt. Een meer exacte benadering daarvan gegeven de gemaakte veronderstellingen lijkt echter wel mogelijk.

In het kader van het onderwerp van dit artikel betekent een en ander, dat toepassing van de aangegeven technieken de ondernemer en de accountant meer zekerheid verschaffen over de mate van onzekerheid inzake het voortbestaan van de onderneming.

De accountant verkrijgt daarmee een sterkere basis voor de constatering, dat situatie 4 van Meningsuiting $\mathrm{nr} 1$ zich voordoet nl. de situatie 'waarin discontinuïteit onvermijdelijk is te achten zonder medewerking van belanghebbenden die verder gaat dan waartoe zij zich tot dusverre hebben verbonden...'

Te gereder kan hij vervolgens de voorwaardelijk goedkeurende verklaring afgeven. Dit grenst aan voorspellen. De accountant moet heel zeker van zijn zaak zijn alvorens hij deze verklaring afgeeft. 
Toch is er ook hier een voorbehoud. Men leze: 'onvermijdelijk is te achten'. Het blijft een schatting, een voorspelling kan het niet zijn.

\section{De accountantsverklaring resp. -mededeling met betrekking tot toekomstverwachtingen}

4. In het voorafgaande werd gesproken over het oordeel van de accountant omtrent de verslaggeving over een verstreken periode. Die verslaggeving betreft feitelijkheden.

Toekomstverwachtingen spelen daarbij een rol maar slechts voorzover van invloed op de waardering van de feitelijkheden. Duurzame productiemiddelen, voorraden, onderhanden werk en vorderingen zijn feitelijkheden op een balansdatum en kunnen door de accountant worden waargenomen en geverifieerd. Dat toekomstschattingen vaak nodig zijn om de waarde vast te stellen doet aan het bestaan van de feitelijkheden niets af. Bij het geven van een oordeel over een verslaggeving vormen de feitelijkheden de deugdelijke grondslag die nodig is voor de totstandkoming van het oordeel.

Bij het oordelen over toekomstverwachtingen ontbreekt deze feitelijke grondslag en ligt de vraag voor de hand of er dan wel sprake kan zijn van een deugdelijke grondslag.

In de behandeling van deze vraag zal achtereenvolgens aandacht worden gegeven aan

- de inhoud van toekomstverwachtingen,

- de uitspraak van de accountant daaromtrent,

- de betekenis van die uitspraak.

5. Hier te lande laten de bestuurders van beursondernemingen zich als regel ten minste twee maal per jaar uit over hun verwachtingen met betrekking tot de toekomst. Te noemen zijn: het halfjaarbericht en de toekomstparagraaf in het jaarverslag.

In het halfjaarbericht wordt mededeling gedaan over het behaalde resultaat in de eerste helft van een boekjaar. Meestal wordt daaraan toegevoegd een mededeling omtrent het verwachte jaarresultaat. Daarbij worden soms bedragen genoemd maar vaak ook niet. In het laatste geval zijn uitlatingen in de trant van: 'het resultaat zal hoger (of lager) zijn dan het vorig jaar' of 'de resultaten ontwikkelen zich bevredigend' e.d. niet ongebruikelijk. De toekomstparagraaf in vele jaarverslagen ziet er in het algemeen niet anders uit. Publicatie van geprognotiseerde resultatenrekeningen of zelfs begrote jaarrekeningen komt in Nederland niet voor.

Dit is begrijpelijk. De ongunstige economische ontwikkelingen in de laatste jaren leiden keer op keer tot teleurstellingen ten opzichte van aanvankelijke verwachtingen. De voorbeelden liggen voor het grijpen: de beweging in de koersen van vreemde valuta, de teruggang in koopkrachtige vraag, de energieprijzen. Daardoor wordt men voorzichtig en aarzelend in zijn uitingen.

Toch dient elke prognose, hoe voorzichtig of vaag ook in zijn bewoordingen, gebaseerd te zijn op een zo goed mogelijk opgestelde begroting. Indien dit niet het geval is mist de prognose een grondslag en is het niet anders dan 
een - op zijn best - gevoelsmatige uitspraak.

Het spreekt vanzelf, dat er verschil in kwaliteit van en mogelijkheden tot het opstellen van begrotingen is. Ten behoeve van het ontwikkelen van een verantwoord bedrijfsbeleid zijn begrotingen van kosten en opbrengsten en dus van resultaten echter onmisbaar en alleen al daarom worden zij gemaakt. Tevens dienen zij dan als uitgangspunt voor een prognose.

Voor ons onderwerp - de accountantsverklaring resp. -mededeling met betrekking tot toekomstverwachtingen - is dit een belangrijk gegeven. De prognose kan vaag en voorzichtig en eventueel zonder vermelding van bedragen zijn geformuleerd. Toch kunnen ook dergelijke uitspraken pas gedaan worden na het opmaken van een begroting. Dit biedt de accountant een aanknopingspunt voor een onderzoek op basis waarvan hij vervolgens misschien een uitspraak kan doen.

6. Kan een accountant een uitspraak over een begroting of een prognose doen? Met andere woorden: zijn prognoses certificeerbaar? Over deze vraag is veel gepubliceerd in de Angelsaksische landen. In Nederland is minder aandacht aan het vraagstuk geschonken, alhoewel er belangwekkende publicaties zijn. Een literatuuroverzicht is te vinden in het academisch proefschrift van R.A.H. van der Meer ${ }^{7}$.

Het antwoord op de vraag hangt - dunkt mij - af van de beoogde inhoud van de uitspraak/certificaat.

Van der Meer noemt drie mogelijke doelstellingen ${ }^{8}$, nl. het weergeven van een oordeel over:

a. de betrouwbaarheid van prognoses,

$b$. de aannemelijkheid van de veronderstellingen waarop prognoses berusten alsmede over de wijze van totstandkoming en presentatie van prognoses,

c. de wijze van totstandkoming en presentatie van prognoses.

Bij doelstelling a. is de uitkomst van de prognose zelf in het geding. Ik meen dat een accountant zich in de uitoefening van zijn functie daarover niet zal mogen uitlaten. In het eerste deel van dit artikel is zulks reeds gebleken. Hij is geen waarzegger.

Zo ook G.G.M. Bak op de Accountantsdag 1977: 'De betekenis van het accountantsoordeel over toekomstgerichte informatie ligt in het oordeel over de weergave van gekwantificeerde verwachtingen binnen de onderneming, niet in het oordeel over deze verwachtingen zelf'. En: 'Met het geven van een oordeel over de verwachting zelf zou de accountant niet alleen de grenzen van zijn kunnen - erger nog! - de grenzen van zijn functie overschrijden ${ }^{9}$.

In het kader van doelstelling b. zou de accountant (mede) een oordeel moeten geven omtrent de aannemelijkheid van de veronderstellingen waarop prognoses berusten.

Tot deze veronderstellingen zullen vrijwel steeds behoren verwachte omzet-, prijs- en marge-ontwikkelingen, die weer samenhangen met de trends in de economie van de landen waarmee een onderneming in zijn bedrijvig- 
heid van doen heeft. Ik meen dat de accountant niet over de deskundigheid beschikt om verwachtingen omtrent conjunctuur- en omzet-ontwikkelingen e.d. te kunnen beoordelen. De accountant zelf zal derhalve geen uitspraak kunnen doen over de aannemelijkheid van veronderstellingen op dit terrein. Wellicht kan hij zich in een grote organisatie andere deskundigen assumeren, die hiertoe in staat zijn. Dit biedt hem echter geen opening om zelf uitspraken over deze onderwerpen te doen in de vorm van accountantsverklaringen of -mededelingen.

In allerlei gevallen kan de accountant weliswaar de arbeid van andere deskundigen benutten voorzover het op onderdelen of in bepaalde aspecten een bijdrage geeft aan zijn eigen oordeelsvorming en vervolgens kan hij zijn eigen oordeel geven.

In het onderhavige geval zou hij echter geheel moeten afgaan op het oordeel van een ander. Het is duidelijk dat hij dit oordeel dan niet als het zijne kan presenteren.

Doelstelling c. - een oordeel over de wijze van totstandkoming en presentatie van prognoses - resteert. Mèt Bak ben ik van mening dat de accountant de kwaliteit van het planning- of besluitvormingsproces ter zake van toekomstgerichte informatie moet kunnen beoordelen. Zeker indien daartoe een team van deskundigen kan worden geformeerd ${ }^{10}$. Het gaat hierbij niet om de uitkomst van de prognose en evenmin om de gemaakte veronderstellingen maar om de procedures die zijn gevolgd en bijv. de consistentheid van toegepaste waarderingen en verstrekte informatie. Het zou te ver voeren hierop nu nader in te gaan.

Er van uitgaande dat de accountant (met zijn team) in staat is op grond van een ingesteld onderzoek tot een oordeel over de procedures etc. te komen, moet hij dit oordeel ook in een uitspraak kunnen formuleren.

Een vraagpunt in Nederlandse accountantskringen is of een dergelijke uitspraak een verklaring is of een niet meer dan een mededeling. Volgens artikel 1 van de GBR wordt onder een verklaring verstaan: 'een schriftelijke mededeling van een acountant inhoudende de uitkomst van een onderzoek naar de getrouwheid van een verantwoording'.

Waar het nu om gaat is of de door een onderneming verstrekte toekomstgerichte informatie (de prognose) als een verantwoording is te beschouwen. Aangezien geen definitie van het begrip verantwoording beschikbaar is rijst een probleem.

Van der Meer heeft de stand van de discussie hierover uitvoerig uit de doeken gedaan ${ }^{11}$. Hij acht het wenselijk prognoses onder het begrip verantwoording te rangschikken.

In 'Neutraal, maar niet passief' wordt dit echter ondoelmatig geoordeeld ${ }^{12}$. Als reden wordt aangegeven, dat bij een prognose geen ondubbelzinnige verklaring (goedkeurend, afkeurend of oordeelonthoudend) kan worden afgegeven. Opgemerkt zou kunnen worden dat over de kwaliteit van het planningsproces - m.a.w. de wijze waarop de prognose tot stand is gekomen - wèl een ondubbelzinnig oordeel kan worden gegeven. Dat is juist maar dan gaat het niet meer om een prognose maar 'slechts' om het proces waarlangs een prognose tot stand is gekomen. Alles wat een accountant 
over dat proces zegt is - bij de gegeven definitie van verklaring - derhalve niet meer dan een mededeling.

Mogelijkerwijs komt het voorgaande als een wat formele redenering over. Dit moge zo zijn, maar zolang art. $1 \mathrm{GBR}$ niet is gewijzigd - hetgeen Bak zo nodig aanbeveelt - kan de inhoud ervan niet terzijde worden gesteld.

Overigens zijn er ook materiële redenen om prognoses niet als een verantwoording te beschouwen.

Voor toekomstgerichte informatie gelden fundamenteel andere eisen dan voor informatie in de jaarrekening, aldus $\mathrm{Bak}^{13}$. Niemand zal dit tegenspreken. Maar dan is het toch ook niet doelmatig beide vormen van informatie onder het ene begrip verantwoording te begrijpen. Daarenboven gaat het in de uitspraak van de accountant over prognoses niet om het gegeven cijfermateriaal resp. de aanduiding daarvan, terwijl dit in de verklaring omtrent de jaarrekening nu juist wel het geval is. Het komt mij doelmatig voor deze uitspraken van geheel verschillende aard dan ook maar aan te duiden met verschillende namen resp. verklaring en mededeling. Daarmede wordt tevens vermeden dat de zekerheid die een accountantsverklaring oproept, althans beoogt op te roepen, ook toegeschreven wordt aan de mededeling van een accountant over prognoses. Die zekerheid kan met een dergelijke mededeling niet worden geboden. Ook daarom is het naar mijn inzicht ongewenst prognoses als een verantwoording aan te merken.

En last but not least blijven wij door dit achterwege te laten in lijn met het spraakgebruik.

De conclusie van dit vrij lange betoog is, dat het technisch mogelijk is voor een accountant (in teamwork) een onderzoek in te stellen naar de procedures en methodieken, die zijn toegepast bij het opstellen van prognoses en de wijze van presentatie van de prognoses zelf. Zo een onderzoek kan leiden tot een oordeel omtrent de onderzochte materie. En dit oordeel kan in een uitspraak onder woorden worden gebracht. Deze uitspraak kan slechts betrekking hebben op de wijze van totstandkoming en presentatie van prognoses en kan niet mede betreffen de prognoses zelf en/of de veronderstellingen waarop de prognoses berusten.

De uitspraak van de accountant is niet als een verklaring in de zin van de GBR te beschouwen omdat het om verschillende redenen niet doelmatig is prognoses als een verantwoording aan te merken ${ }^{14}$.

7. Ten slotte maak ik nog enkele opmerkingen over de betekenis van de accountantsmededeling omtrent prognoses in de beperkte strekking, zoals omschreven in het vorige punt.

Een onderneming kan in zijn jaarverslag een geprojecteerde jaarrekening voor het volgende jaar opnemen. Ook kan - en dat is bijna het andere uiterste - worden volstaan met de simpele uitspraak, dat de resultaten zich in het komende jaar op een lager niveau zullen bewegen dan in het verslagjaar.

De accountant kan zowel bij het ene stuk als bij de andere eenvoudige uitspraak mededelen dat de wijze van totstandkoming en de presentatie 
van de prognose op verantwoorde wijze is geschied. Het staat voor mij vast dat de gebruikers van de jaarverslagen enige betekenis toekennen aan deze accountantsmededeling. Zij mogen daaruit afleiden dat de prognose niet zomaar een gissing is, maar gebaseerd is op redelijke voorafgaande arbeid bij het opstellen van begrotingen.

Maar het gevaar is levensgroot, dat de betekenis van de accountantsmededeling wordt overtrokken en met name wordt uitgebreid tot een goedkeuring (bijkans een voorspelling) van het bedrag van de prognose ${ }^{15}$. Daarom is er in accountantskringen een aarzeling om mededelingen over prognoses te doen. In de praktijk, althans in Nederland, worden dergelijke mededelingen nauwelijks aangetroffen. Voor de praktijk in het buitenland zij verwezen naar het proefschrift van Van der Meer. De aarzeling bestaat niet alleen bij accountants. Ook de ondernemers zelf hebben hun twijfels over de betekenis van uitspraken over de toekomst. De radicale omslag in de economische ontwikkelingen gedurende de laatste jaren hebben het hunne daaraan duidelijk bijgedragen.

Moet hieruit worden afgeleid, dat ondernemers maar moeten stoppen met het doen van prognoses en moeten accountants vergeten, dat zij ooit daarbij mededelingen zullen afgeven?

Deze vraag moet ontkennend worden beantwoord.

Reeds werd opgemerkt dat begrotingen onmisbaar zijn als richtsnoer voor het bedrijfsbeleid. En de begrotingen komen bij de voortgaande ontwikkeling van de medezeggenschap binnen de ondernemingen in steeds meer handen en zijn meer en meer onderwerp van overleg en mede-oordelen door werknemers, al dan niet georganiseerd in ondernemingsraden.

De prognoses af te leiden uit de begrotingen zijn als gevolg hiervan bij velen bekend.

Velen leren uit de praktijk ook dat prognoses een beperkte betekenis hebben en zeker niet als voorspellingen mogen worden beschouwd. Naarmate dit proces van bewustwording ten aanzien van de merites van begrotingen en prognoses in brede kring voortschrijdt kunnen deze instrumenten van bedrijfsbeleid meer open boek worden.

Gaandeweg vermindert dan ook het gevaar dat aan mededelingen van accountants bij begrotingen en prognoses een overtrokken betekenis wordt toegekend. De gebruikers van deze mededelingen zijn zich dan bewust van de inhoud van het motto, waarmee dit artikel begon: de accountant spreekt de waarheid, maar hij is geen waarzegger.

\section{Noten}

1 Accountantsverklaringen bij jaarrekeningen in situaties van onzekerheid. Ontwerp ter discussie 13; september 1981. Voorbereid door de Commissie Controlevraagstukken van het NIURA.

2 Neutraal, maar niet passief. Rapport van de Werkgroep Dynamische Functie-analyse september $1980 \mathrm{blz} .59$ en 60 .

3 De inhoud van de accountantsverklaring bij de jaarrekening van ondernemingen met continuitteitsproblemen. Meningsuiting nr 1 van het NIvRA juli 1977.

4 A. de Jong, De voorwaardelijke verklaring. MAB april 1981. A. J. Bosman, De inhoud van de accountantsverklaring bij de jaarrekening van ondernemingen. MAB januari 1982. A.J. Bosman, Meldingsplicht van ondernemingen met continuiteitsproblemen? MAB februari 1982. 
5 R. A. J. van Frederikslust en M. A. van Hoepen, Discriminantanalyse en de accountantsverklaring bij de jaarrekening van ondernemingen met continuitteitsproblemen. MAB november 1981.

6 Zie 5, blz. 564 en 565 .

7 R. A. H. van der Meer, Enige beschouwingen omtrent prognoses in het jaarverslag en de certificeerbaarheid daarvan 1981.

8 Zie 7, blz. 194.

9 G. G. M. Bak, Mogelijkheden en grenzen van de accountant bij prognoses. Prae-advies Accountantsdag 1977 blz. 11 en 15.

10 Zie 9, blz. 15 en 16.

11 Zie 7 , blz. 205 tot 210

12 Zie 2, blz. 131 en 132.

13 Zie 9, blz. 11.

14 Geheel anders oordeelt Van der Meer. Op blz. 282 van zijn proefschrift geeft hij een uitvoerige tekst van een accountantsverklaring bij een geprojecteerde jaarrekening in overweging.

$15 \mathrm{~A} . J$. Bosman, The expanding borders of accounting - Are we trying to measure the immeasurable? Prae-advies voor de 3e Jeruzalem Conferentie van Accountants 1978. Opgenomen in het MAB maart 1979 blz. 104.

Zie 2, blz. 143.

C. Dubbeld, De attestfunctie in ontwikkeling. MAB juli/augustus 1980 blz. 362 en 363. 